\title{
Fluoxetine regulates glucose and lipid metabolism via the PI3K-AKT signaling pathway in diabetic rats
}

\author{
HAILONG YANG $^{1}$, QIUYUN CAO ${ }^{2}$, XIAOLU XIONG $^{3}$, PENG ZHAO $^{2}$, \\ DIWEN SHEN ${ }^{2}$, YUZHE ZHANG ${ }^{2}$ and NING ZHANG ${ }^{4}$ \\ ${ }^{1}$ Department of Clinical Psychology, Nanjing Drum Tower Hospital Clinical College of Nanjing Medical University; \\ Departments of ${ }^{2}$ Clinical Psychology and ${ }^{3}$ Endocrinology, Nanjing Drum Tower Hospital Affiliated to \\ Nanjing University Medical College; ${ }^{4}$ Department of Clinical Psychology, Nanjing Brain Hospital \\ Affiliated to Nanjing Medical University, Nanjing, Jiangsu 210000, P.R. China
}

Received February 28, 2018; Accepted November 1, 2018

DOI: $10.3892 / \mathrm{mmr} .2020 .11416$

\begin{abstract}
Diabetes mellitus poses a major threat towards global heath due to a lack of effective treatment. Fluoxetine hydrochloride, a selective 5-hydroxytryptamine reuptake inhibitor, is the most commonly used antidepressant in clinical therapy; however, the potential molecular mechanisms of fluoxetine in diabetes remain unknown. In the present study, reduced glucose, total cholesterol and triglyceride levels and lipid metabolism, as well as upregulated proliferator-activated receptor $\gamma$, fatty acid synthase and lipoprotein lipase, and downregulated sterol regulatory element-binding protein 1 -c were detected in rats with streptozotocin (STZ)-induced diabetes following treatment with fluoxetine. Furthermore, fluoxetine significantly inhibited the expression levels of glucose metabolism-associated proteins in liver tissues, including glycogen synthase kinase $3 \beta$ (GSK-3 $\beta$ ), glucose- 6 phosphatase catalytic subunit (G6PC), phosphoenolpyruvate carboxykinase (PEPCK) and forkhead box protein O1 (FOXO1). In addition, fluoxetine treatment notably attenuated morphological liver damage in rats with STZ-induced diabetes. Additionally, fluoxetine could inhibit the phosphatidylinositol 3-kinase-protein kinase B (PI3K-AKT) signaling pathway, whereas LY294002, a specific inhibitor of PI3K, suppressed the function of PI3K-AKT signaling and suppressed the expression levels of glucose metabolism-associated proteins, including GSK-3 $\beta$, G6PC, PEPCK and FOXO1 in BRL-3A cells. The results of the present study revealed that fluoxetine may regulate glucose and lipid metabolism via the PI3K-AKT signaling pathway in diabetic rats.
\end{abstract}

Correspondence to: Professor Ning Zhang, Department of Clinical Psychology, Nanjing Brain Hospital Affiliated to Nanjing Medical University, 264 Guangzhou Road, Nanjing, Jiangsu 210000, P.R. China

E-mail: zn6360@126.com

Key words: fluoxetine, diabetes mellitus, lipid metabolism, phosphoinositide 3-kinase, protein kinase B

\section{Introduction}

Diabetes mellitus (DM) poses a major threat towards global health. At present, the number of patients with diabetes has reached 180 million worldwide, of which type 2 diabetes (T2DM) accounts for $>90 \%$ of cases (1). Among numerous factors, insulin resistance serves an important role in the development of T2DM (2). Previous studies have revealed that T2DM not only induces physical symptoms, cell functional damage and self-management capacity decline, but also results in uncontrolled blood glucose and cardiovascular complications, consequently increasing mortality $(3,4)$. It has been reported that the severity of T2DM is strongly associated with the control of blood glucose in patients with T2DM (5). As it is important to improve the prognosis of T2DM patients, treatment with long-term use of antidepressant drugs is essential.

Fluoxetine, a selective 5-hydroxytryptamine (5-HT) reuptake inhibitor, is the most commonly used drug for the treatment of patients with T2DM (6). A recent study revealed that fluoxetine hydrochloride can improve glucose tolerance and insulin resistance (7). Ghaeli et al (8) has reported that non-diabetic patients orally administered fluoxetine exhibit reduced levels of fasting blood glucose. In addition, a meta-analysis based on five large-scale clinical trials has indicated that fasting blood glucose and triglycerides are significantly decreased in T2DM patients treated with fluoxetine hydrochloride compared with a placebo group $(9,10)$. In addition, fluoxetine hydrochloride can increase insulin sensitivity (11-13). These results suggest that fluoxetine may improve insulin resistance and the therapeutic outcome of non-depressed patients with T2DM; however, the roles of fluoxetine in reducing blood glucose, weight loss and improving insulin resistance, as well as the underlying mechanisms remain unknown.

The liver is the major organ that produces glucose via gluconeogenesis and glycogenolysis (13). A previous study has revealed that at the early stage of hepatosteatosis, patients are often unaware of their impaired insulin sensitivity (14); the functions of the liver in the insulin-resistant state remain unknown. The phosphatidylinositol 3-kinase-protein kinase B (PI3K-AKT) signaling pathway serves an important role in 
glucose synthesis and uptake and gluconeogenesis in the liver; the PI3K-AKT pathway also promotes adipose formation by stimulating insulin and regulating the functions of fat $(15,16)$. In the present study, the effects of fluoxetine on fasting blood sugar and glucolipid metabolism in diabetic rats were investigated.

\section{Materials and methods}

Animal models and experimental designs. The present study was conducted using male Sprague-Dawley rats $(n=24$; age, 6-weeks; weight, 180-220 g), provided by the Model Animal Research Institute of Nanjing University (Nanjing, China). The rats were divided into four groups: i) Control; ii) $\mathrm{DM}$; iii) $\mathrm{DM}+20 \mathrm{mg} / \mathrm{kg}$ fluoxetine (H-fluoxetine); and iv) $\mathrm{DM}+40 \mathrm{mg} / \mathrm{kg}$ fluoxetine (L-fluoxetine). The mice were maintained under standard laboratory conditions under a $12 \mathrm{~h}$ light/dark cycle with adequate temperature $\left(25^{\circ} \mathrm{C}\right)$ and humidity (45-55\%), and free access to food and water. The present study was approved by the Ethics Committee of Nanjing Medical University (Nanjing, China).

The rats were treated with streptozotocin (STZ; $60 \mathrm{mg} \mathrm{kg}$ ) in citrate buffer ( $\mathrm{pH} 4.5)$ via an intraperitoneal injection within $15 \mathrm{~min}$ of dissolution. The control group was treated with citrate buffer alone. After 3 weeks of stimulation with STZ, rats with a random blood glucose value of $300 \mathrm{mg} / \mathrm{dl}$ were considered to have STZ-induced diabetes. Then, STZ-treated rats were injected intraperitoneally with 20 or $40 \mathrm{mg} / \mathrm{kg}$ fluoxetine (Sun Pharmaceutical Industries Ltd., Mumbai, India) once a day for 21 days.

Determination of glucose and glucolipid metabolism. Blood samples were obtained from the rats and centrifuged at $1,509 \mathrm{x} \mathrm{g}$ for $15 \mathrm{~min}$ at $4^{\circ} \mathrm{C}$. Then, the sera were used to evaluate the levels of total cholesterol (TC; cat. no. A111-1), triglyceride (TG; cat. no. A110-1) and fasting blood glucose (FBG; cat. no. F006-1-1) using enzymatic assays (Nanjing Jiancheng Bioengineering Institute, Nanjing, China), according to the manufacturer's protocols. The fasting insulin (FINS) level was estimated using a ELISA kit (cat. no. JCSW2610) provided by Shanghai Jichun Industrial Co., Ltd. Insulin resistance was estimated using a homeostasis model, as described previously (17).

Insulin tolerance test (ITT) and intraperitoneal glucose tolerance test (IPGTT). Rats were fasted overnight and then anesthetized; insulin $(0.5 \mathrm{UI} / \mathrm{kg})$ was injected intravenously into the tail vein. Blood collection were performed via the tail vein, and the concentration of blood glucose was evaluated at $0,15,30,60,90$ and 120 min using a Biosen glucose analyzer (EKF-diagnostic GmbH). Prior to the IPGTT, rats were fasted overnight and anesthetized, and blood samples were obtained. Then, $1 \mathrm{~g} / \mathrm{kg}$ glucose was injected intraperitoneally. Blood samples were collected and glucose levels were determined at $0,15,30,60,90$ and $120 \mathrm{~min}$. Blood glucose was measured according to the manufacturer's protocol (Biosen glucose analyzer; EKF-diagnostic GmbH).

Pathological analysis. Following sacrifice, the liver tissues of rats were obtained and fixed using $4 \%$ paraformaldehyde for
$24 \mathrm{~h}$ at $25^{\circ} \mathrm{C}$, and then dehydrated, embedded in paraffin and sliced into sections of $4 \mu \mathrm{m}$ thickness, which were subjected to hematoxylin and eosin staining for $1 \mathrm{~min}$ at $25^{\circ} \mathrm{C}$. The overall histological features (magnification, x200) were observed and recorded via a light microscope (Olympus Corporation, Tokyo, Japan); five fields in each image were analyzed.

Oil Red $O$ staining. The liver tissues of rats were embedded in optimal cutting temperature compound (Sakura Finetek USA, Inc.), snap-frozen and sliced into 5- $\mu \mathrm{m}$ sections, which were stained for $1 \mathrm{~h}$ at $25^{\circ} \mathrm{C}$ using an Oil Red $\mathrm{O}$ staining kit (Nanjing KeyGen Biotech Co., Ltd.). The staining (magnification, x200) was visualized by light microscopy (Olympus Corporation). The percentage of red staining in five fields of each image was determined using Image Pro Plus 6.0 (Media Cybernetics, Inc.).

Immunohistochemistry staining. The method of immunohistochemistry was performed as previously described (18). The liver tissues of rats were fixed using $4 \%$ paraformaldehyde for $30 \mathrm{~min}$ at $25^{\circ} \mathrm{C}$, and then dehydrated, embedded in paraffin and sliced into sections of $4 \mu \mathrm{m}$ thickness. Sections were deparaffinized with xylene and were incubated with primary antibodies against phosphorylated (p)-PI3K (1:500; cat. no. ab182651; Abcam, Cambridge, MA, USA), PI3K (1:500; cat. no. ab135253; Abcam), p-Thr308-AKT (p-AKT; 1:500; cat. no. ab8933; Abcam), and AKT (1:500; cat. no. ab8805; Abcam) overnight at $4^{\circ} \mathrm{C}$, followed by incubation with a horseradish peroxidase-conjugated secondary antibody $(1: 2,000$; cat. nos. ab214880 and ab97040; Abcam) for $2 \mathrm{~h}$ at $25^{\circ} \mathrm{C}$. Then, the sections were incubated using a 3,3'-diaminobenzidine kit (Vector Laboratories, Inc.) according to the manufacturer's protocols. The expression of each protein was observed by light microscopy (Olympus Corporation); five fields in each image were analyzed. The findings were analyzed determined using Image Pro Plus 6.0.

Cell culture and treatment. The BRL-3A rat normal liver cell line was purchased from American Type Culture Collection. Cells were cultured in Dulbecco's modified Eagle's medium (Gibco; Thermo Fisher Scientific, Inc.) supplemented with $10 \%$ fetal bovine serum (Gibco; Thermo Fisher Scientific, Inc.) at $37^{\circ} \mathrm{C}$ in an atmosphere containing $5 \% \mathrm{CO}_{2}$. Cells were maintained in high glucose $(30 \mathrm{mM})$ in the presence or absence of fluoxetine (30 $\mu \mathrm{M}$; Sigma-Aldrich; Merck KGaA, Darmstadt, Germany) or LY294002 (30 $\mu \mathrm{M}$; Sigma-Aldrich) at $37^{\circ} \mathrm{C}$ for $24 \mathrm{~h}$. Subsequently, the expression levels of associated proteins were detected.

Western blotting. Total proteins were extracted from liver tissues or BRL-3A cells using different methods as previously described $(14,15)$. The proteins were quantified using the bicinchoninic acid assay (Applygen Technologies, Inc.). The samples $(30 \mu \mathrm{g})$ were separated using $10 \%$ SDS-PAGE and transferred onto polyvinylidene difluoride membranes, which were then blocked with skimmed milk for $1 \mathrm{~h}$ at $25^{\circ} \mathrm{C}$ and incubated at $4^{\circ} \mathrm{C}$ overnight with primary antibodies as follows: GAPDH (1:5,000; cat. no. ab9485; Abcam), glycogen synthase kinase $3 \beta$ (GSK-3 $\beta ; 1: 2,000$; cat. no. ab93926; Abcam), glucose-6 phosphatase catalytic subunit (G6PC; 

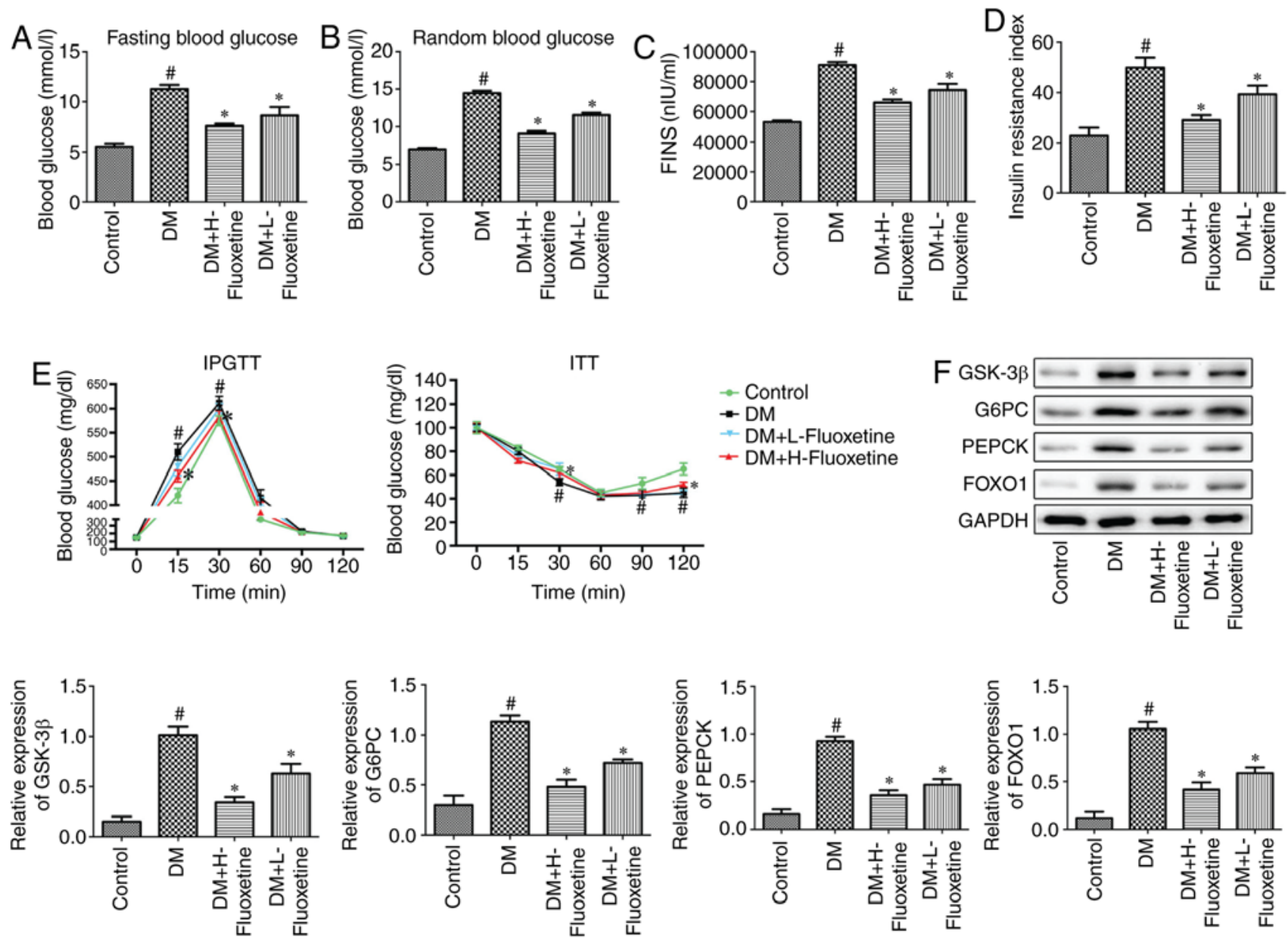

Figure 1. Effects of fluoxetine treatment on blood glucose in rats with STZ-induced diabetes. (A) Fluoxetine reduced the levels of fasting blood glucose rats with STZ-induced diabetes. (B) Effects of fluoxetine on the levels of random blood glucose in rats with STZ-induced diabetes. (C) Fluoxetine downregulated the levels of FIN in rats with STZ-induced diabetes. (D) Effects of fluoxetine on the insulin resistance index in rats with STZ-induced diabetes. (E) Fluoxetine improved intraperitoneal glucose tolerance and insulin tolerance in rats with STZ-induced diabetes. (F) Effects of fluoxetine on the expression levels of glucose metabolism-associated proteins in rats with STZ-induced diabetes. ${ }^{\#} \mathrm{P}<0.05$ vs. the control group. ${ }^{*} \mathrm{P}<0.05$ vs. the $\mathrm{DM}$ group. DM, diabetes mellitus; FOXO1, forkhead box protein O1; G6PC, glucose-6 phosphatase catalytic subunit; GSK-3 $\beta$, glycogen synthase kinase $3 \beta$; H-fluoxetine, 20 mg/kg fluoxetine; L-fluoxetine, $40 \mathrm{mg} / \mathrm{kg}$ fluoxetine; PEPCK, phosphoenolpyruvate carboxykinase; STZ, streptozotocin.

1:2,000; cat. no. ab133964; Abcam), phosphoenolpyruvate carboxykinase (PEPCK; 1:2,000; cat. no. ab70359; Abcam), forkhead box protein O1 (FOXO1; 1:2,000; cat. no. ab52857; Abcam), sterol regulatory element-binding protein 1-c (SREBP1-c; 1:2,000; cat. no. ab28481; Abcam), peroxisome proliferator-activated receptor $\gamma(\operatorname{PPAR} \gamma ; 1: 2,000$; cat. no. ab59256; Abcam), fatty acid synthase (FAS; 1:2,000; cat. no. ab82419; Abcam), lipoprotein lipase (LPL; 1:2,000; cat. no. ab21356; Abcam), PI3K (1:2,000; cat. no. ab135253; Abcam), AKT (1:2,000; cat. no. ab8805; Abcam), p-PI3K (1:2,000; cat. no. ab182651; Abcam) and p-AKT (1:2,000; cat. no. ab8933; Abcam). The membranes were washed in tris-buffered saline with $0.05 \%$ Tween-20 for three times and incubated with horseradish peroxidase-conjugated secondary antibody (1:2,000; cat. nos. ab97040 and ab99697; Abcam) for $2 \mathrm{~h}$ at $25^{\circ} \mathrm{C}$. The bands were visualized by using an enhanced chemiluminescence protein detection kit (Beyotime Institute of Biotechnology). GAPDH was used to normalize protein expression. Densitometry analysis was performed using ImageJ 6.0 software (National Institutes of Health) and the experiment was repeated at least three times.
Statistical analysis. Statistical analysis was performed using GraphPad Prism 5.0 (GraphPad Software, Inc.). Each experiment was repeated at least three times and data were presented as the mean \pm standard deviation. When only two groups were compared, a Student's t-test was used. One-way ANOVA followed by Tukey's test was applied to compare differences between multiple groups. $\mathrm{P}<0.05$ was considered to indicate a statistically significant difference.

\section{Results}

Effects of the treatment with fluoxetine on blood glucose in rats with $S T Z$-induced diabetes. FBG in rats treated with STZ or fluoxetine were examined. As presented in Fig. 1A, the levels of FBG were significantly increased in diabetic rats compared with the control $(\mathrm{P}<0.05)$; however, the levels were significantly reduced following the treatment with fluoxetine. In addition, the levels of random blood glucose were determined, and similar effects were observed (Fig. 1B). Furthermore, the levels of FINS in rats were evaluated. The levels of FINS were significantly increased in diabetic rats compared with 
A

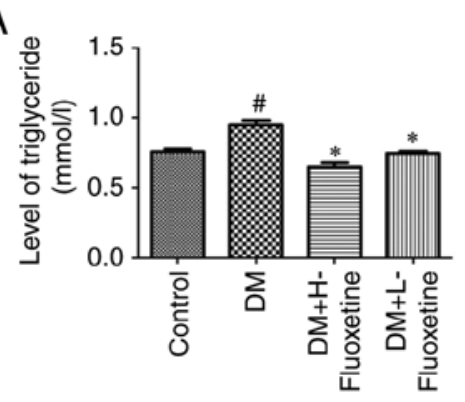

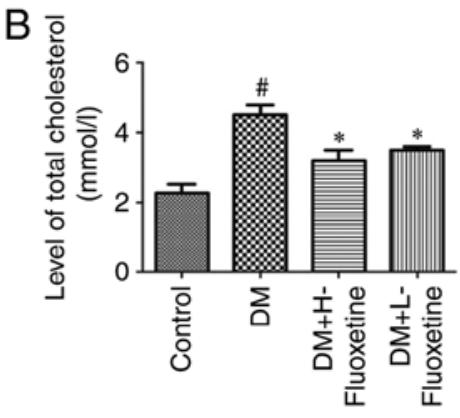
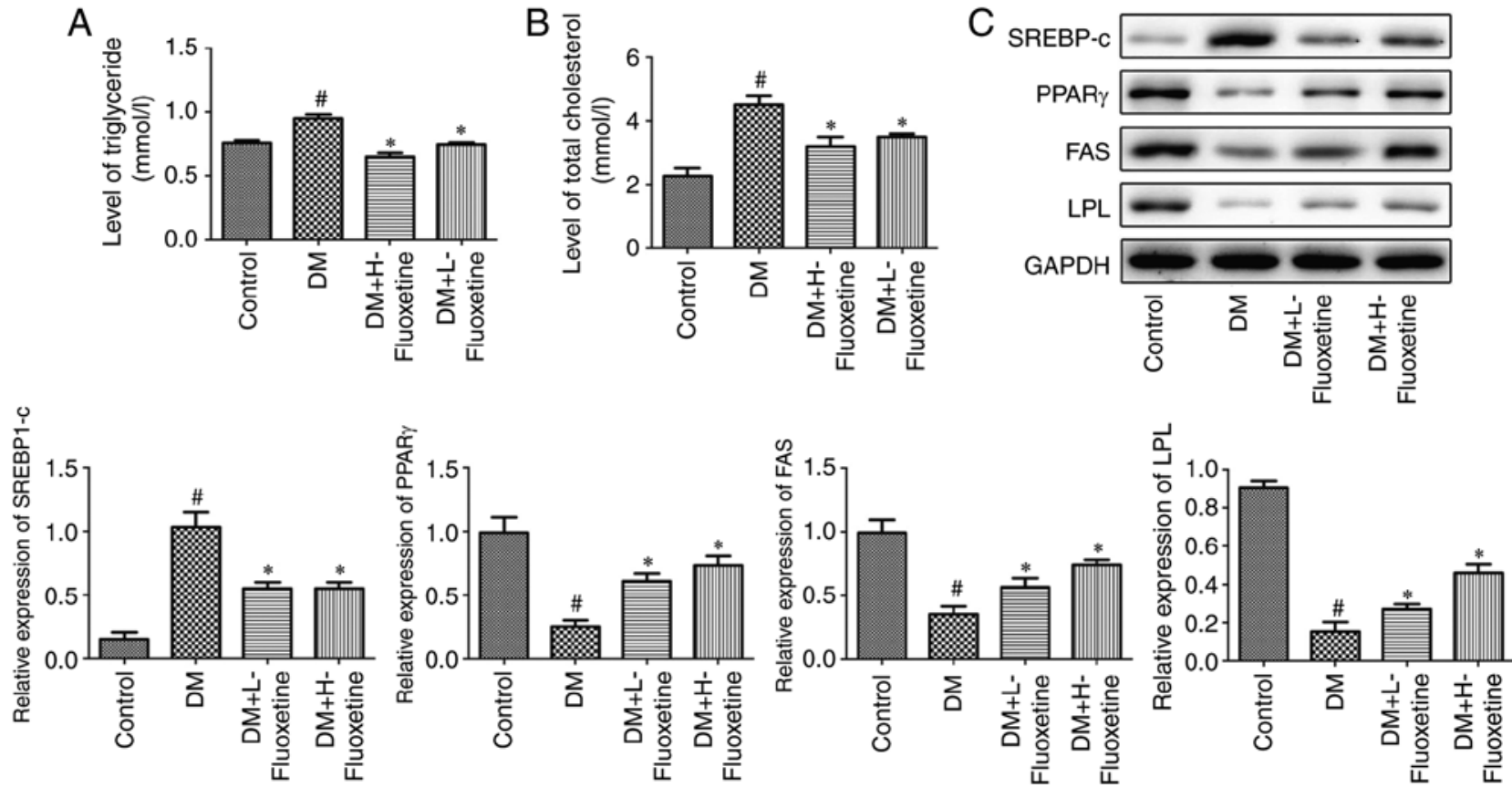

Figure 2. Effects of fluoxetine on lipid metabolism in rats with STZ-induced diabetes. (A) Fluoxetine suppressed the levels of triglyceride in rats with STZ-induced diabetes. (B) Fluoxetine reduced the levels of total cholesterol in rats with STZ-induced diabetes. (C) Effects of fluoxetine on the expression levels of glucose metabolism-associated proteins in rats with STZ-induced diabetes. ${ }^{*} \mathrm{P}<0.05$ vs. the control group. ${ }^{*} \mathrm{P}<0.05$ vs. the DM group. DM, diabetes mellitus; FAS, fatty acid synthase; H-fluoxetine, $20 \mathrm{mg} / \mathrm{kg}$ fluoxetine; L-fluoxetine, $40 \mathrm{mg} / \mathrm{kg}$ fluoxetine; LPL, lipoprotein lipase; PPAR $\gamma$, peroxisome proliferator-activated receptor $\gamma$; SREBP-1c, sterol regulatory element-binding protein 1-c; STZ, streptozotocin.

the control $(\mathrm{P}<0.05)$, while significantly decreased levels were observed in the fluoxetine-treated groups compared with the DM group (Fig. 1C). Additionally, the insulin resistance index was evaluated. The results revealed that the resistance index was significantly increased in diabetic rats compared with normal rats $(\mathrm{P}<0.05)$; however, the index was significantly reduced by treatment with fluoxetine (Fig. 1D).

IPGTT and ITT were performed to investigate the function of fluoxetine in rats. The results revealed that fluoxetine treatment significantly improved insulin and glucose tolerance (Fig. 1E). In addition, the expression levels of glucose metabolism-associated proteins GSK-3 $\beta$, G6PC, PEPCK and FOXO1 were significantly increased in diabetic rats compared with the control $(\mathrm{P}<0.05)$, whereas the effects of STZ-induced diabetes were significantly abolished following treatment with fluoxetine (Fig. 1F).

Effects of fluoxetine on lipid metabolism in rats with STZ-induced diabetes. Numerous pathways are involved in the development of diabetes, including insulin secretion, insulin signaling, glycolysis and lipid metabolism $(19,17)$. To investigate the extent of lipid metabolism, the expression levels of associated proteins were evaluated in rats. As presented in Fig. 2A and B, the levels of TG and TC in sera were significantly increased in diabetic rats compared with the control $(\mathrm{P}<0.05)$, while the effects were abolished in the fluoxetine-treated groups. In addition, the expression levels of PPAR $\gamma$, FAS and LPL were significantly downregulated in diabetic rats $(\mathrm{P}<0.05)$, whereas $\mathrm{SREBP} 1-\mathrm{c}$ was upregulated in diabetic rats compared with the control; however, the expression profile of the proteins was reversed following treatment with fluoxetine (Fig. 2C).
Fluoxetine attenuates liver morphology damage and lipid accumulation in rats with STZ-induced diabetes. To investigate the underlying mechanisms of fluoxetine on insulin resistance, the present study selected the liver for analysis as it participates in glucose and lipid metabolism (20). Thus, liver morphology and lipid accumulation were evaluated. As presented in Fig. 3A, liver cells were disorderly arranged in diabetic rats compared with the control; cell swelling, sparse cytoplasm and necrosis of liver cells were also observed in diabetic rats. Fewer disordered liver cells and reduced necrosis were detected in fluoxetine-treated rats. Lipid accumulation in liver sections was indicated by Oil Red $\mathrm{O}$ staining. The lipid content was increased in diabetic rats, whereas treatment with fluoxetine notably decreased the lipid content (Fig. 3B).

Fluoxetine affects the PI3K-AKT signaling pathway in in rats with STZ-induced diabetes. It has previously been indicated that the PI3K-AKT signaling pathway serves a vital role in the liver; dysregulated signaling can lead to impaired glucolipid metabolism, resulting in liver insulin resistance (21). The expression levels of p-PI3K and p-AKT were notably upregulated in diabetic rats compared with the control (Fig. 4A); however, reduced expression of $\mathrm{p}-\mathrm{PI} 3 \mathrm{~K}$ and $\mathrm{p}$-AKT was observed in diabetic rats following treatment with fluoxetine. The expression levels of AKT in the diabetic rats appeared notably unchanged, whereas PI3K expression was markedly increased. Treatment with fluoxetine revealed a marked increase in the expression of AKT and reduced PI3K expression. The ratios of p-PI3K/PI3K and p-AKT/AKT were significantly increased in diabetic rats compared with the control ( $\mathrm{P}<0.05$; Fig. 4B); the ratios were significantly reduced following treatment with fluoxetine compared with in diabetic rats. 
A

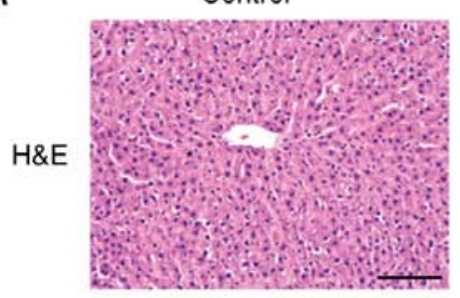

B

Oil red

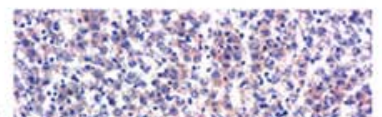

DM
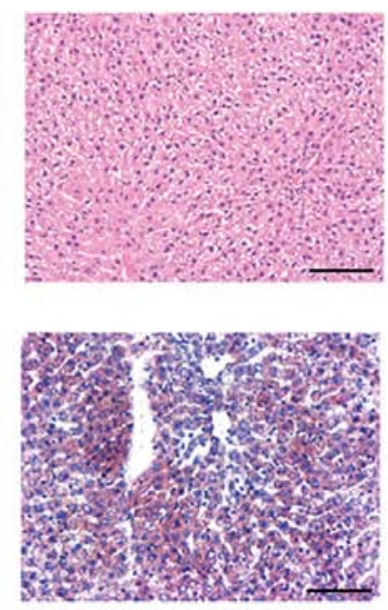

DM+H-Fluoxetine
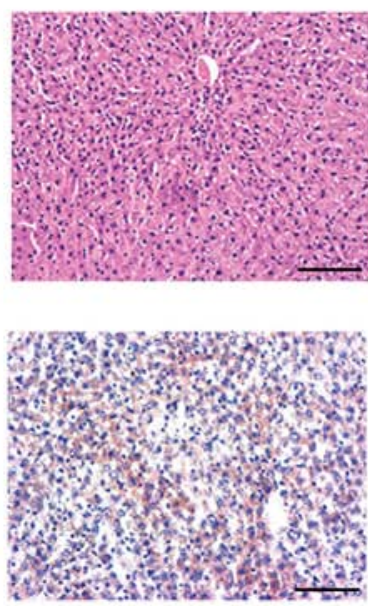

$\mathrm{DM}+\mathrm{L}-$ Fluoxetine
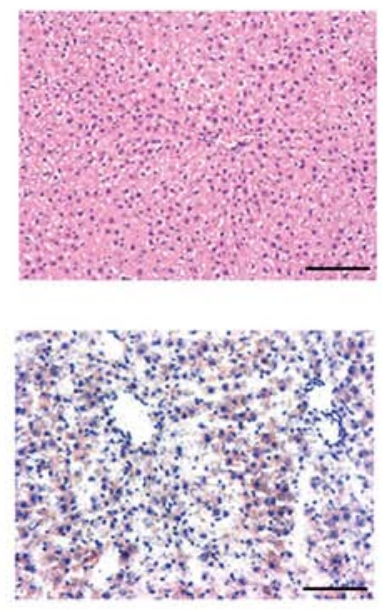

Figure 3. Fluoxetine attenuates liver morphology damage and lipid accumulation in rats with STZ-induced diabetes. (A) Hematoxylin and eosin staining revealed cellular morphology in diabetic liver tissues. (B) Oil Red O staining indicated lipid accumulation in diabetic rats. Scale bar, $100 \mu \mathrm{m}$. DM, diabetes mellitus; H-fluoxetine, $20 \mathrm{mg} / \mathrm{kg}$ fluoxetine; L-fluoxetine, $40 \mathrm{mg} / \mathrm{kg}$ fluoxetine; STZ, streptozotocin.

A
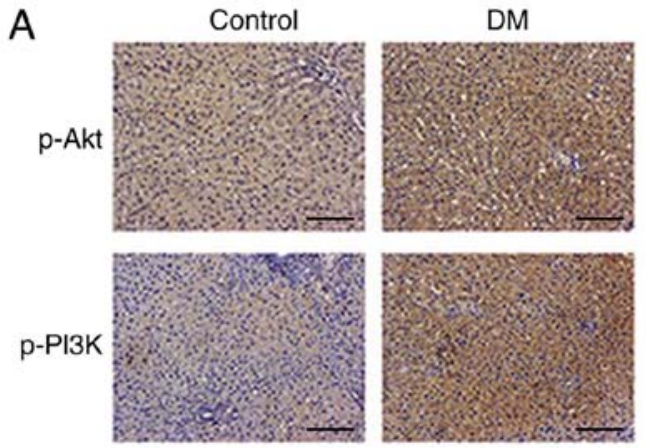

$\mathrm{DM}+\mathrm{H}-$ Fluoxetine
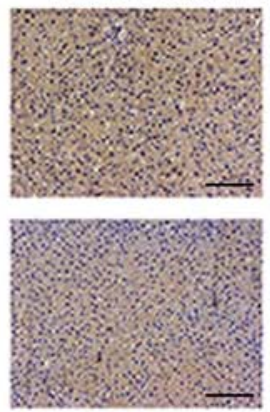

B
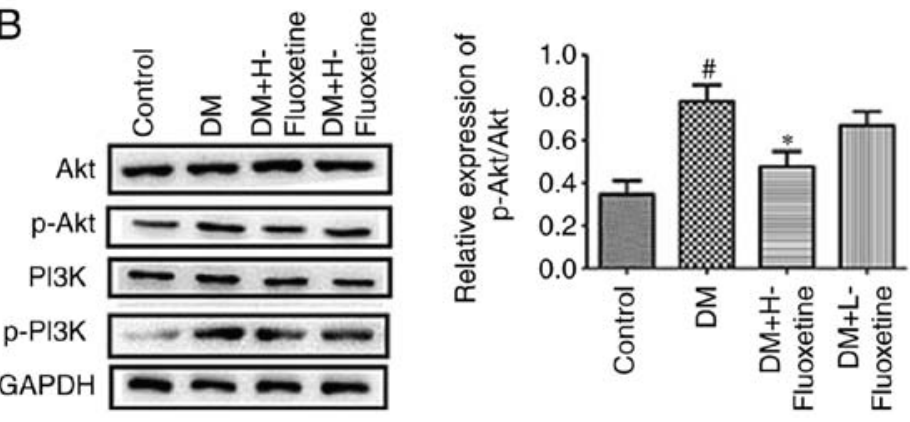
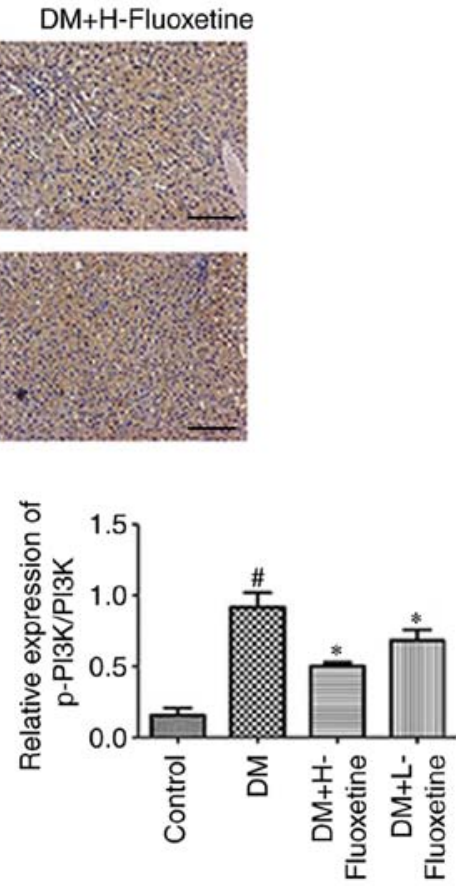

Figure 4. Fluoxetine affects the PI3K-AKT signaling pathway in rats with STZ-induced diabetes. (A) Immunohistochemistry staining was used to analyze the proteins associated with PI3K-AKT pathway. Scale bar, $100 \mu \mathrm{m}$. (B) Western blotting revealed the expression levels of proteins involved in the PI3K-AKT signaling pathway; the ratio of $\mathrm{p}-\mathrm{AKT} / \mathrm{AKT}$ and $\mathrm{p}-\mathrm{PI} 3 \mathrm{~K} / \mathrm{PI} 3 \mathrm{~K}$ are presented. ${ }^{~} \mathrm{P}<0.05$ vs. the control group. ${ }^{\mathrm{P}} \mathrm{P}<0.05$ vs. the DM group. DM, diabetes mellitus; H-fluoxetine, $20 \mathrm{mg} / \mathrm{kg}$ fluoxetine; L-fluoxetine, $40 \mathrm{mg} / \mathrm{kg}$ fluoxetine; PI3K-AKT, phosphatidylinositol 3-kinase-protein kinase B; p-, phosphorylated; STZ, streptozotocin.

LY294002 enhances the effects of fluoxetine on glucose and lipid metabolism. LY294002 is a specific inhibitor of PI3K, which suppresses the PI3K-AKT signaling pathway. To investigate the molecular mechanisms of fluoxetine on insulin resistance, BRL-3A cells were maintained in high glucose in the presence or absence of fluoxetine or LY294002. The expression levels of glucose metabolism-associated proteins, including GSK-3 $\beta$, G6PC, PEPCK and FOXO1 were evaluated by western blotting. The protein expression levels, including GSK-3 $\beta$, G6PC, PEPCK and FOXO1, were significantly increased in the DM group compared with in the control group, while expression was significantly reduced following the treatment with fluoxetine and LY294002 (P<0.05; Fig. 5A). Besides, the expression levels of PPAR $\gamma$ and FAS were significantly decreased in the DM group compared with in the control group, whereas treatment with fluoxetine and LY294002 reversed these effects. Additionally, the ratios of p-AKT/AKT and $\mathrm{p}$-PI3K/PI3K were significantly increased in the DM group compared with in the control group, whereas treatment with fluoxetine and LY294002 significantly decreased the protein levels of p-PI3K and p-AKT compared with in the DM group (Fig. 5B). 

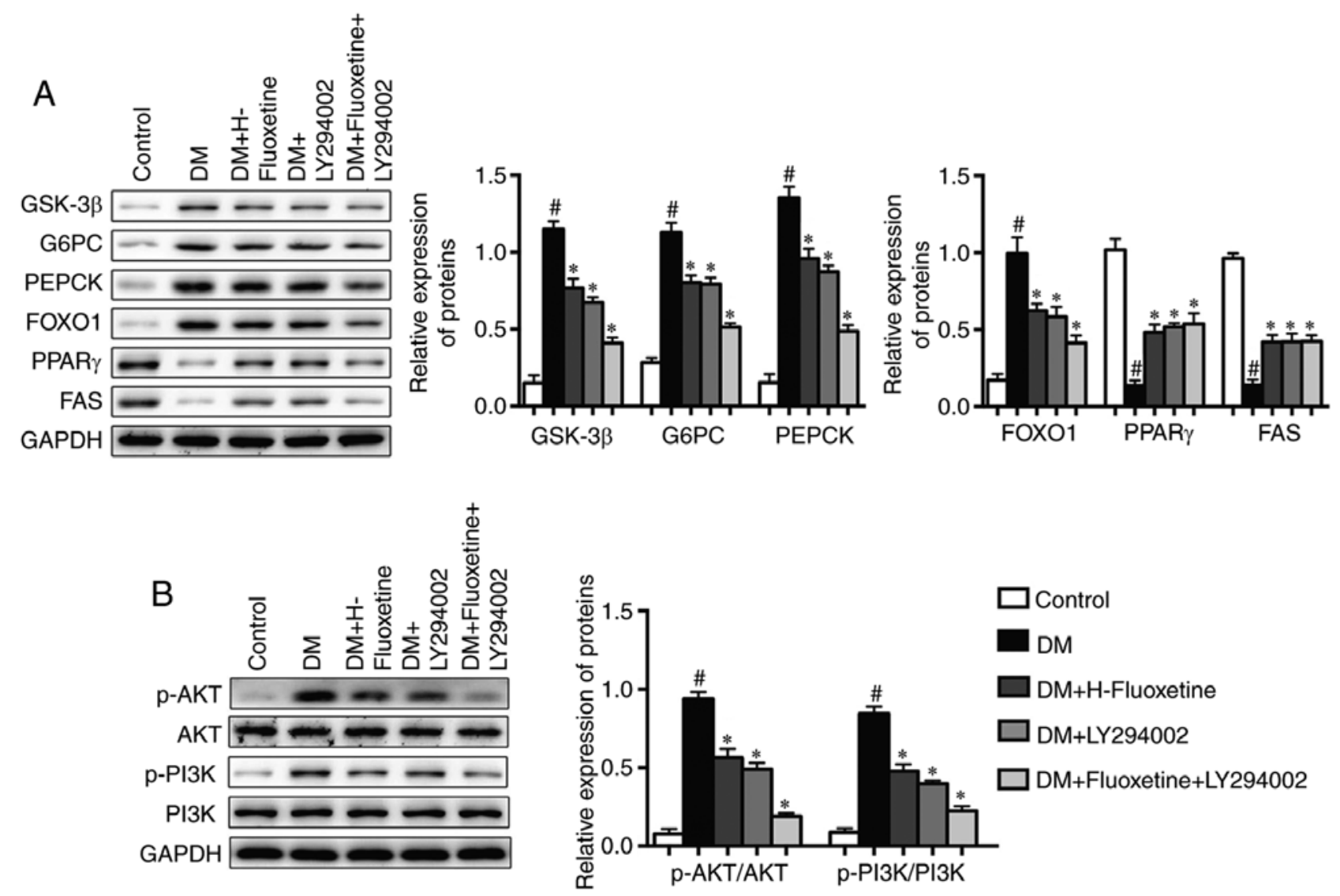

Figure 5. LY294002 enhances the effects of fluoxetine on glucose and lipid metabolism. (A) Western blotting revealed the expression levels of glucose metabolism-associated proteins. (B) Western blotting indicated the expression levels of proteins involved in the PI3K-AKT signaling pathway. ${ }^{\prime \prime} \mathrm{P}<0.05$ vs. the control group. " $\mathrm{P}<0.05$ vs. the DM group. DM, diabetes mellitus; GSK-3 $\beta$, glycogen synthase kinase $3 \beta$; G6PC, guocose-6 phosphatase catalytic subunit; H-fluoxetine, $20 \mathrm{mg} / \mathrm{kg}$ fluoxetine; FAS, fatty acid synthase; FOXO1, forkhead box protein O1; L-fluoxetine, $40 \mathrm{mg} / \mathrm{kg}$ fluoxetine; PEPCK, phosphoenolpyruvate carboxykinase; PI3K-AKT, phosphatidylinositol 3-kinase-protein kinase B; p-PI3K, phosphorylated PI3K; p-AKT, phosphorylated AKT; PPAR $\gamma$, peroxisome proliferator-activated receptor $\gamma$.

\section{Discussion}

Diabetes is a chronic disease, and there is no effective treatment for diabetes apart from long-term diet control or the administration of insulin $(22,23)$. Long-term treatment serves a vital role in the treatment of diabetes (24). T2DM can result in disorders of glycolipid metabolism and insulin resistance $(25,26)$, consequently leading to increased blood glucose and weight loss, which lead to adverse effects in patients with T2DM.

Selective serotonin reuptake inhibitors are antidepressants used for the treatment of anxiety disorders (27). Fluoxetine, a selective 5-HT reuptake inhibitor, is the most commonly used drug to treat patients with T2DM $(28,29)$. Ghaeli et al $(8)$, reported that oral administration of fluoxetine in non-diabetic patients decreased the levels of FBG. In addition, a meta-analysis based on five large-scale clinical trials revealed that the levels of FBG and TG were significantly reduced in patients with T2DM following treatment with fluoxetine hydrochloride compared with a placebo $(9,10)$; however, the effects of fluoxetine on lipid metabolism and the underlying mechanisms remain unknown. In the present study, STZ-induced T2DM rats were used to mimic the metabolic characteristics of T2DM as reported previously (30); the effects of fluoxetine on glucose and lipid metabolism were investigated (31). Additionally, the levels of FBG and random glucose were significantly decreased in STZ-induced T2DM rats following treatment with fluoxetine hydrochloride in the present study, indicating that fluoxetine may reduce hyperglycemia and increase insulin sensitivity; the molecular mechanisms may be associated with muscle glycogen synthesis (32). Park et al (33), revealed that 90\% pancreatic resection increased glucose clearance and decreased blood insulin levels following 8 weeks of fluoxetine treatment. Tembhurne et al (34) reported that fluoxetine reduced the levels of FBG and improved glucose tolerance in rats with STZ-induced diabetes. In summary, fluoxetine may reduce blood glucose and body weight loss, and improve insulin resistance; however, the underlying molecular mechanisms remain unknown.

The liver participates in glucose and lipid metabolism $(35,36)$. In the present study, liver tissue morphology and lipid accumulation were investigated, and the potential roles of fluoxetine were determined. Liver cells were disorderly arranged; cell swelling, sparse cytoplasm and necrosis of liver cells were observed in diabetic rats. A reduction in the number of aberrant liver cells and necrosis were detected in fluoxetine-treated rats. The present study hypothesized that lipid accumulation in the liver may increase insulin resistance and affect glucose metabolism. Numerous genes serve crucial roles in the regulation of hepatic glucose and lipid metabolism. For instance, G6PC, PEPCK and GSK-3 $\beta$ are involved 
in hepatic carbohydrate metabolism (37-39). FAS and LPL are associated with lipid metabolism $(40,41)$. In addition, various studies investigated the association between fluoxetine and lipid metabolism in liver toxicity $(20,42)$; PPAR $\gamma$ may be involved in these processes (43). In the present study, the results revealed that GSK-3 $\beta$, G6PC, PEPCK and FOXO1 were upregulated in diabetic rats, whereas the effects were inhibited following treatment with fluoxetine. Additionally, the expression levels of PPAR $\gamma$, FAS and LPL were downregulated, whereas SREBP1-c was upregulated in diabetic rats compared with the control; however, the expression profile of these proteins were reversed following fluoxetine treatment.

Previous studies revealed that the PI3K/AKT signaling pathway served a critical role in the liver, and disrupted signaling may lead to impaired glycolipid metabolism and result in insulin resistance of the liver $(44,45)$. In the present study, fluoxetine inhibited the phosphorylation of PI3K and AKT, and suppressed the PI3K/AKT signaling pathway. The activation of this signaling pathway can alter glucose and lipid metabolism in the liver, subsequently enhancing the sensitivity to insulin and improving insulin resistance (46). In the present study, primary hepatocytes of type 2 diabetic rats were isolated and treated with fluoxetine and PI3K inhibitor LY294002 in vitro. The results revealed that LY294002 downregulated the expression of glucose metabolism-associated proteins in rats with STZ-induced diabetes. In summary, the results of the present study demonstrated that fluoxetine treatment may improve the symptoms of diabetes via regulating the PI3K-AKT signaling pathway.

\section{Acknowledgements}

Not applicable.

\section{Funding}

The research was supported by the Medical Science and Technology Development Foundation, Nanjing Department of Health (grant no. YKK15055).

\section{Availability of data and materials}

All data generated or analyzed during this study are included in this published article.

\section{Authors' contributions}

HY, QC and NZ designed the experiments. XX, PZ and DS performed the experiments. YZ made substantial contributions in analyzing the data. HY drafted the manuscript. All authors read and approved the final manuscript.

\section{Ethics approval and consent to participate}

The present study was approved by the Ethics Committee at Nanjing Medical University (Nanjing, China).

\section{Patient consent for publication}

Not applicable.

\section{Competing interests}

The authors declare that they have no competing interests.

\section{Reference}

1. Prevention of diabetes mellitus. Report of a WHO Study Group. World Health Organ Tech Rep Ser 844: 1-100, 1994.

2. Yang SH, Dou KF and Song WJ: Prevalence of diabetes among men and women in China. N Engl J Med 362: 2425-2426, author reply 2426, 2010.

3. Kawada T: Depression and type 2 diabetes. Prim Care Diabetes 11: 212, 2017.

4. Zhang Y, Ting RZW, Yang W, Jia W, Li W, Ji L, Guo X, Kong APS, Wing YKW, Luk AOY, et al; China Depression in Chinese Patients with Type 2 Diabetes (DD2) Study Group: Depression in Chinese patients with type 2 diabetes: Associations with hyperglycemia, hypoglycemia, and poor treatment adherence. J Diabetes 7: 800-808, 2015.

5. Otieno CF, Kanu JE, Karari EM, Okech-Helu V, Joshi MD and Mutai K: Glucose-lowering therapies, adequacy of metabolic control, and their relationship with comorbid depression in outpatients with type 2 diabetes in a tertiary hospital in Kenya. Diabetes Metab Syndr Obes 10: 141-149, 2017.

6. Raeder MB, Bjelland I, Emil Vollset S and Steen VM: Obesity, dyslipidemia, and diabetes with selective serotonin reuptake inhibitors: The Hordaland Health Study. J Clin Psychiatry 67: 1974-1982, 2006

7. Moosa MY, Panz VR, Jeenah FY and Joffe BI: African women with depression: The effect of imipramine and fluoxetine on body mass index and leptin secretion. J Clin Psychopharmacol 23: 549-552, 2003.

8. Ghaeli P, Shahsavand E, Mesbahi M, Kamkar MZ, Sadeghi M and Dashti-Khavidaki S: Comparing the effects of 8-week treatment with fluoxetine and imipramine on fasting blood glucose of patients with major depressive disorder. J Clin Psychopharmacol 24: 386-388, 2004.

9. Magni LR, Purgato M, Gastaldon C, Papola D, Furukawa TA, Cipriani A and Barbui C: Fluoxetine versus other types of pharmacotherapy for depression. Cochrane Database Syst Rev 17: CD004185, 2013.

10. Cipriani A, Brambilla P, Furukawa T, Geddes J, Gregis M, Hotopf M, Malvini L and Barbui C: Fluoxetine versus other types of pharmacotherapy for depression. Cochrane Database Syst Rev 19: CD004185, 2005.

11. Breum L, Bjerre U, Bak JF, Jacobsen S and Astrup A: Long-term effects of fluoxetine on glycemic control in obese patients with non-insulin-dependent diabetes mellitus or glucose intolerance: Influence on muscle glycogen synthase and insulin receptor kinase activity. Metabolism 44: 1570-1576, 1995.

12. Connolly VM, Gallagher A and Kesson CM: A study of fluoxetine in obese elderly patients with type 2 diabetes. Diabet Med 12: 416-418, 1995.

13. O'Kane M, Wiles PG and Wales JK: Fluoxetine in the treatment of obese type 2 diabetic patients. Diabet Med 11: 105-110, 1994.

14. Huang W, Zhao Y, Zhu X, Cai Z, Wang S, Yao S, Qi Z and Xie P: Fluoxetine upregulates phosphorylated-AKT and phosphorylated-ERK1/2 proteins in neural stem cells: Evidence for a crosstalk between AKT and ERK1/2 pathways. J Mol Neurosci 49: 244-249, 2013.

15. Briscoe VJ, Ertl AC, Tate DB and Davis SN: Effects of the selective serotonin reuptake inhibitor fluoxetine on counterregulatory responses to hypoglycemia in individuals with type 1 diabetes. Diabetes 57: 3315-3322, 2008.

16. Voellinger R, Berney A, Baumann P, Annoni JM, Bryois C, Buclin T, Büla C, Camus V, Christin L, Cornuz J, et al: Major depressive disorder in the general hospital: Adaptation of clinical practice guidelines. Gen Hosp Psychiatry 25: 185-193, 2003.

17. Tang XW and Qin QX: miR-335-5p induces insulin resistance and pancreatic islet $\beta$-cell secretion in gestational diabetes mellitus mice through VASH1-mediated TGF- $\beta$ signaling pathway. J Cell Physiol 234: 6654-6666, 2019.

18. Zhang YN, Dong HT, Yang FB, Wang ZQ, Ma ZH, Ma SZ, Ma XD and Duan L: Nrf2-ARE signaling pathway regulates the expressions of A1R and ENT1 in the brain of epileptic rats. Eur Rev Med Pharmacol Sci 22: 6896-6904, 2018.

19. Tang D, Liu L, Ajiakber D, Ye J, Xu J, Xin X and Aisa HA: Anti-diabetic effect of Punica granatum flower polyphenols extract in type 2 diabetic rats: Activation of Akt/GSK-3 $\beta$ and inhibition of IRE1 $\alpha$-XBP1 pathways. Front Endocrinol (Lausanne) 9: 586, 2018. 
20. Pan SJ, Tan YL, Yao SW, Xin Y, Yang X, Liu J and Xiong J: Fluoxetine induces lipid metabolism abnormalities by acting on the liver in patients and mice with depression. Acta Pharmacol Sin 39: 1463-1472, 2018.

21. Han C, Wei S, Song Q, He F, Xiong X, Wan H, Liu D, Ye F, Liu $\mathrm{H}, \mathrm{Li} \mathrm{L}$, et al: Insulin stimulates goose liver cell growth by activating PI3K-AKT-mTOR signal pathway. Cell Physiol Biochem 38: 558-570, 2016.

22. Whittier AB, Gelaye B, Deyessa N, Bahretibeb Y, Kelkile TS, Berhane $\mathrm{Y}$ and Williams MA: Major depressive disorder and suicidal behavior among urban dwelling Ethiopian adult outpatients at a general hospital. J Affect Disord 197: 58-65, 2016.

23. Beyazyüz M, Albayrak Y, Eğilmez OB, Albayrak N and Beyazyüz E: Relationship between SSRIs and metabolic syndrome abnormalities in patients with generalized anxiety disorder: A prospective study. Psychiatry Investig 10: 148-154, 2013.

24. Xing S and Lee TA: Increased risk of diabetes among 6-24-year-olds using second generation antipsychotics. J Child Adolesc Psychopharmacol 27: 782-791, 2017.

25. Wang Y, Lopez JM, Bolge SC, Zhu VJ and Stang PE: Depression among people with type 2 diabetes mellitus, US National Health and Nutrition Examination Survey (NHANES), 2005-2012. BMC Psychiatry 16: 88, 2016.

26. Isaac R, Boura-Halfon S, Gurevitch D, Shainskaya A, Levkovitz Y and Zick Y: Selective serotonin reuptake inhibitors (SSRIs) inhibit insulin secretion and action in pancreatic $\beta$ cells J Biol Chem 288: 5682-5693, 2013.

27. Macías-Cortés ED, Llanes-González L, Aguilar-Faisal L and Asbun-Bojalil J: Is metabolic dysregulation associated with antidepressant response in depressed women in climacteric treated with individualized homeopathic medicines or fluoxetine? The HOMDEP-MENOP Study. Homeopathy 106: 3-10, 2017.

28. Chen YC, Shen YC, Hung YJ, Chou CH, Yeh CB and Perng $\mathrm{CH}$ Comparisons of glucose-insulin homeostasis following maprotiline and fluoxetine treatment in depressed males. J Affect Disord 103: 257-261, 2007.

29. Zheng XK, Zhang L, Wang WW, Wu YY, Zhang QB and Feng WS: Anti-diabetic activity and potential mechanism of total flavonoids of Selaginella tamariscina (Beauv.) Spring in rats induced by high fat diet and low dose STZ. J Ethnopharmacol 137: 662-668, 2011

30. Ma H, You GP, Zhang XP, Yang XJ, Lu HD, Huang YL and Zhang WQ: A novel role of globular adiponectin in treatment with HFD/STZ induced T2DM combined with NAFLD rats. ScientificWorldJournal 2014: 230835, 2014.

31. Potter van Loon BJ, Radder JK, Frölich M, Krans HM, Zwinderman AH and Meinders AE: Fluoxetine increases insulin action in obese nondiabetic and in obese non-insulin-dependent diabetic individuals. Int J Obes Relat Metab Disord 16: 79-85, 1992.

32. Potter van Loon BJ, Radder JK, Frölich M, Krans HM, Zwinderman $\mathrm{AH}$ and Meinders AE: Fluoxetine increases insulin action in obese type II (non-insulin dependent) diabetic patients. Int J Obes Relat Metab Disord 16 (Suppl 4): S55-S61, 1992.

33. Park S and Choi SB: Does fluoxetine administration influence insulin resistance in $90 \%$ pancreatectomized rats? Metabolism 51: $38-43,2002$
34. Tembhurne SV and Sakarkar DM: Effect of fluoxetine on an experimental model of diabetes-induced neuropathic pain perception in the rat. Indian J Pharm Sci 73: 621-625, 2011.

35. Janssens S,HeemskerkMM, van den Berg SA, van RielNA, Nicolay K, Willems van Dijk K and Prompers JJ: Effects of low-stearate palm oil and high-stearate lard high-fat diets on rat liver lipid metabolism and glucose tolerance. Nutr Metab (Lond) 12: 57, 2015.

36. Komshilova KA, Troshina EA, Ershova EV, Mazurina NV and Platonova NM: Adiponectin and parameters of glucose and lipid metabolism at different clinical and morphological stages of non-alcoholic fatty liver disease in patients with abdominal obesity. Ter Arkh 86: 27-32, 2014 (In Russian).

37. Schilling MM, Oeser JK, Chandy JK, Flemming BP, Allen SR and O'Brien RM: Sequence variation between the mouse and human glucose-6-phosphatase catalytic subunit gene promoters results in differential activation by peroxisome proliferator activated receptor gamma coactivator-1alpha. Diabetologia 51: 1505-1514, 2008.

38. Kobayashi M, Ikegami H, Fujisawa T, Nojima K, Kawabata Y, Noso S, Babaya N, Itoi-Babaya M, Yamaji K, Hiromine Y, et al: Prevention and treatment of obesity, insulin resistance, and diabetes by bile acid-binding resin. Diabetes 56: 239-247, 2007.

39. Cohen P and Frame S: The renaissance of GSK3. Nat Rev Mol Cell Biol 2: 769-776, 2001.

40. Chakravarthy MV, Pan Z, Zhu Y, Tordjman K, Schneider JG, Coleman T, Turk J and Semenkovich CF: 'New' hepatic fat activates PPARalpha to maintain glucose, lipid, and cholesterol homeostasis. Cell Metab 1: 309-322, 2005.

41. Socquard E, Durlach A, Clavel C, Nazeyrollas P and Durlach V. Association of HindIII and PvuII genetic polymorphisms of lipoprotein lipase with lipid metabolism and macrovascular events in type 2 diabetic patients. Diabetes Metab 32: 262-269, 2006.

42. Bai S, Zhou C, Cheng P, Fu Y, Fang L, Huang W, Yu J, Shao W, Wang X, Liu M, et al: $1 \mathrm{H}$ NMR-based metabolic profiling reveals the effects of fluoxetine on lipid and amino acid metabolism in astrocytes. Int J Mol Sci 16: 8490-8504, 2015.

43. Berthiaume J and Wallace KB: Perfluorooctanoate, perflourooctanesulfonate, and N-ethyl perfluorooctanesulfonamido ethanol; peroxisome proliferation and mitochondrial biogenesis. Toxicol Lett 129: 23-32, 2002.

44. Ueno S, Saito S, Wada T, Yamaguchi K, Satoh M, Arai Y and Miyagi T: Plasma membrane-associated sialidase is up-regulated in renal cell carcinoma and promotes interleukin-6-induced apoptosis suppression and cell motility. J Biol Chem 281: 7756-7764, 2006.

45. Hale A, Corral RM, Mencacci C, Ruiz JS, Severo CA and Gentil V: Superior antidepressant efficacy results of agomelatine versus fluoxetine in severe MDD patients: A randomized, double-blind study. Int Clin Psychopharmacol 25: 305-314, 2010.

46. Peng J, Li Q, Li K, Zhu L, Lin X, Lin X, Shen Q, Li G and Xie X: Quercetin improves glucose and lipid metabolism of diabetic rats: Involvement of Akt signaling and SIRT1. J Diabetes Res 2017: $3417306,2017$.

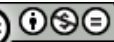

This work is licensed under a Creative Commons Attribution-NonCommercial-NoDerivatives 4.0 International (CC BY-NC-ND 4.0) License. 